\title{
Matter in Scientific Definitions in Aristotle ${ }^{1}$
}

Michail Peramatzis

\begin{abstract}
This article distinguishes between the different types of definition discussed in Aristotle's Posterior Analytics II.10, and argues that only some of them are, strictly speaking, scientific: those which are closely linked to explanatory proofs that latch on the causes of a definiendum's nature. It discusses how these scientific definitions account for different types of entity: processes, artefacts, natural substance-kinds, and the essences or forms of substance-kinds. It gives a brief clarification of Aristotelian hylomorphism, and provides some examples of the concept of matter as understood within hylomorphism. Finally, it examines whether, and if so, how matter may be mentioned in a scientific definition, and addresses several problems arising from Aristotle's overall hylomorphic picture, and the role of matter in it.
\end{abstract}

\section{Keywords}

definition, science, demonstration, proof, explanation, cause, causation, essence, form, matter, compound, hylomorphism

\section{Different Types of Scientific Definition}

The most promising starting-point for a study of Aristotle's view of scientific definition is Posterior Analytics II.10. In this chapter Aristotle distinguishes four different types of definition as follows: ${ }^{2}$ 
(1) Accounts which describe what a name (term) or another name-like expression signifies. ${ }^{3}$ These could be labelled 'semantic' definitions. Thus, for instance, the semantic definition of the term 'triangle' would be:

The term 'triangle' signifies a closed three-sided (or three-angled) plane figure. Or, perhaps more neutrally:

The term 'triangle' signifies the same as the phrase 'a closed three-sided (or threeangled) plane figure' does. ${ }^{4}$

While these definitions may be important for scientific inquiry into the existence and essence of the corresponding kinds (the entities referred to by the relevant terms), they are not, strictly speaking, scientific. ${ }^{5}$ For, as Aristotle argues, we cannot on the basis of them alone possess knowledge of the existence or the essence of a kind as they are not properly related to the appropriate demonstrative route to such knowledge. Rather, they signify without showing or proving anything (93b32-94a1). Simply put: they are not about scientific, existing kinds, but about linguistic terms.

(2) Accounts which reveal why the definiendum exists, or why it is as it is. While type (1) definitions do not show or prove anything, type (2) definitions are like demonstrations of the what-it-is, or the essence, which differ from demonstrations in the arrangement or position of their constituent terms (93b38-94a7). These could be called 'causal definitions'. In Aristotle's own example, the proof which shows the cause of the process-type thunder is shaped as follows:

Noise (of type $N$ ) belongs to all cases of fire being quenched (of type $Q$ ).

Fire being quenched (of type $Q$ ) belongs to all cases of clouds (of type $C$ ).

Noise (of type $N$ ) belongs to all cases of clouds (of type $C$ ).

The causal definition of thunder, by contrast, runs thus: 
Thunder $_{[\text {TYPE }]}=_{\text {def }}$ noise (of type $N$ ) in the clouds (of type $C$ ) brought on by fire being quenched (of type $Q$ ). ${ }^{6}$

The main differences between these two formulae are indeed structural. While the first is a proof (an Aristotelian syllogistic demonstration), involving two premisses with a shared middle term, and a conclusion, the second is a single definitory account, involving all the terms of the proof without itself being a proof. Further, while the proof is about the meteorological phenomenon, the process-type thunder, it does not make any explicit reference to it. The definition, by contrast, is not simply about thunder; it is of thunder, and so the term 'thunder' figures in it as the definiendum-term. This, to be sure, does not imply that the link between the proof about thunder, and the phenomenon thunder is loose or incidental. Rather, the proof works against the background of a semantic, type (1) definition of the form "the term "thunder" signifies the same as the term "a certain type of noise in the clouds" does'. If so, the link between the major and the minor premisses of the proof, as well as its conclusion, on the one hand, and thunder, on the other, is strong. For the noise and the clouds picked up by the major and the minor terms are the ones mentioned in the semantic definition of the term 'thunder'. Moreover, the conclusion of the proof is a more precise and determinate form of this semantic definition.

The proof, then, does indeed show why thunder exists, or why it is as it is, by establishing that the relevant noise belongs to the clouds: it underpins the existence of the kind related to the term 'thunder', and also brings out the cause of its being a certain sort of cloud noise. In Aristotle's view, this sort of cause is captured by the middle term of explanatory proofs (APo II.2, 89b36-90a23; II.11, 94a20-4; 35-6; 94b7-8). The causal definition, on the other hand, shows not only that thunder is a certain cloud noise but also why it is so: due to the relevant kind of fire quenching bringing about this sort of noise in the clouds. 
(3) Accounts which coincide with the conclusions of the demonstrations which are counterparts to type (2) definitions (94a7-9). Thus, for instance, the process-type thunder can also be defined as follows:

Thunder ${ }_{[\mathrm{TYPE}]}=_{\mathrm{def}}$ a noise (of type $N$ ) belonging to (or: in) the clouds (of type $C$ ). It should be noted that this definition -let us label it 'definitory conclusion'- is only superficially similar to the semantic definition of the term 'thunder':

The term 'thunder' signifies the same as the term 'noise in the clouds' does. Even if we expressed this last semantic definition by using (not mentioning) the term 'thunder', the differences between it and the definitory conclusion would be significant. First, the semantic definition does not seem to presuppose the existence of any determinate type of cloud noise that would be identical with the process-type thunder. For the definiens-phrase 'noise in the clouds' is a generic term which could be describing several different phenomena, some related, others irrelevant to, thunder; or it could fail to describe any phenomenon at all. Thus, the semantic definition does not imply the existence of one single kind of thing, or even the existence of anything at all. Furthermore, while the definitory conclusion involves specific or determinate terms picking up the process-type thunder, and some of its essential features (its being a specific sort of cloud noise), the semantic definition does no such thing. For the latter does not contain the proper characterisations of the type of noise or clouds (what the dummy letters $N$ and $C$ are alluding to in the above examples). Finally, and most importantly, the semantic definition, even if read 'use-wise', just is not the conclusion of a proof. Unlike the definitory conclusion, it does not presuppose that there is a cause (picked up by the middle term of a proof) which brings about the relevant noise in the clouds; it does not establish the truth of the noise's belonging to the clouds; nor does it treat the noise's belonging to the clouds as an established 'fact', as an existent type of phenomenon. $^{7}$ 
(4) Indemonstrable accounts or posits of the what-it-is or essence of 'immediate' entities

(94a9-10). These 'immediate' items are primary entities, basic things within specific

scientific domains. They are called 'immediate' because in their case there is no middle term such that it could pick up any cause prior to them, which would be responsible for their existence, or their being as they are. This is in contrast to definitions of types (2) and (3): for in both (2) and (3) there is a middle term picking up a prior cause, and there is a corresponding proof codifying this causal structure. Following some of Aristotle's own examples in the Posterior Analytics, we could think of the following as an 'immediate definition' (APo. II.9, 93b24-5):

To be a unit $=_{\text {def }}$ to be indivisible in quantity.

Indeed, the unit is a primary item in the domain of number-theory. For there does not seem to be any numerical entity which could be responsible for its existence, or its being as it is. By contrast, the unit itself seems to be (directly or indirectly) responsible for the rest of the items studied by number-theory, their existence, and their essential or necessary features. For, presumably, it is ultimately on the basis of the unit and its nature that proofs are constructed within the domain of number-theory.

It is important, at this juncture, to gesture towards another central distinction drawn in the present context of the Posterior Analytics, in chapters II.8-9. This distinction is crucial for understanding the contrast between definitions of type (4), and those of types (2) and (3). In his discussion of the relation of demonstration to definition, Aristotle maintains that the essence of a (kind of) thing is inextricably linked to, if not identical with, the cause of its existence, and its being as it is. He also remarks that this cause is either something different from the thing or 'the same' (APo. II.8, 93a3-6). Similarly, he distinguishes between cases in which there is a cause different from the thing, and those in which there is not. Here the cause seems to be the cause of thing's essence, or its being what it is (APo. II.9, 93b21; 25-7). This 
is a difficult distinction. The cases in which the cause is different from the thing are unproblematic. In definitions of types (2) and (3) the thing, thunder, or the noise's belonging to the clouds, indeed has a different cause for its being what it is: the fire's being quenched in the clouds. For this last (what is picked up by the middle term of the proof) is precisely what brings about the process of thunder, or the noise's belonging to the clouds. Presumably, it also is responsible for the nature of this type of process. But what about the cases in which the cause is not different from the thing? Do these imply that the thing itself is the cause of its very own nature? This seems incoherent: for a cause is prior to the thing it causes, such that it cannot, on pain of contradiction, be the cause of itself. The relation of causation, no matter how widely we may understand it, seems irreflexive.

It is important to note, however, that Aristotle does not claim that in these last cases the cause of a thing (or of its what-it-is) is the same as the thing itself. He holds simply that there is no other cause. This need not entail that the thing is its own cause. Rather, it suggests that the thing is such that there is nothing prior to it, nothing which could be a cause of, or account for, its nature. Furthermore, such things seem to be primary or fundamental: for they are prior to, and causes of, all other things within a certain scientific domain, while the converse is not the case. This is why there is no 'other cause'. Indeed, at APo. II.9, 93b21-22, Aristotle makes this point clearer. Things for which there is no other cause are those essences (tôn ti esti) which are immediate and principles. Presumably, they are principles, primary, or basic in that they are causes for the nature of everything else in a certain domain, while there is nothing (amongst items in that domain) which could serve as a cause for them (or their nature). Further, they are immediate as there is no middle term which could latch onto any such 'other' cause. Nor is there any corresponding demonstration in which such a middle term would be embedded. It seems reasonable to conclude that such primary or immediate 
essences are described by immediate definitions, those of type (4), such as the definition of unit offered earlier.

The distinction between the different sorts of scientific definition will be crucial for the present study. The questions of whether matter is present in Aristotle's scientific definitions, and if so, how it is present obviously depend on what Aristotle takes scientific definitions to be. As noted, semantic definitions do not seem to be, strictly speaking, scientific. For this reason they will be mostly disregarded in what follows. Definitions of types (2)-(4), however, are indeed scientific. Roughly speaking, there are two main reasons for this. First, they are of existents: their definiendum is an existent type of thing. Second, they are strongly linked to scientific demonstration. This is not just a matter of any aesthetic attraction that proof, or the notion of proof, may exert on knowers such as ourselves. Rather, it is grounded on the notion of causation inherent in scientific demonstrations. As the examples provided earlier suggest, the middle terms of proofs refer to causes which bring about certain other things - phenomena, processes, or what have you- and also underwrite the nature (the what-it-is or essence) of these things. This seems clear in types (2) and (3). But in type (4), too, while there is no correlate demonstration, or prior cause, yet the definitions pick up essences which themselves are causes for the nature of other, derivative things. Similarly, while type (4) definitions have no counterpart proof in which the middle term picks up the cause of the nature of the definiendum (for there is no such 'other cause'), they themselves could operate as (direct or indirect) grounds for all other proofs in the relevant domain. For, they themselves are the ultimate cause for the nature of other things in a given domain, just as being a unit, or being an indivisible quantity, seems the fundamental entity underpinning all other numerical entities, their nature and necessary features. ${ }^{8}$

\section{Matter in Definitions of Process-Kinds}


As a first case of definiendum it is useful to discuss processes such as thunder, always focusing on types or kinds, leaving to the side the difficult questions of whether there are definitions of tokens (particular or individual instances), and if so, what their formulation would be. To come to grips with the question of whether and how matter is present in definitions of process-types it is important, first, to clarify briefly Aristotle's conception of matter. The precise content of this notion is an extremely demanding issue which will not be treated in any detail at present. Some examples, however, will be sufficient to stir up an intuitive grasp of the concept of matter. Thus, for instance, matter seems to be a component, or a constituent of perceptible, material, and changeable objects, such as natural things (humans, horses, etc.) or artefacts (chairs, tables, statues, etc.). These objects could be understood either as tokens or particulars (Socrates, Bucephalus, the Hermes of Praxiteles, etc.), or as the corresponding types (the human kind, the kind horse, the kind Hermes statue, etc.). Analogously, we may speak of matter as token materials, or bodily bits (e.g., Socrates' body, the marble constituting the Hermes of Praxiteles), or as type matter (e.g., the human body, marble, etc.). A further important distinction is that between the matter which actually constitutes a living body (my functioning human body), or a 'working' artefact (the stuff making up a functioning table), and is present in the actual object, and the matter from which a living body comes to be (the human seed and egg), or from which an artefact is produced (the planks of wood which were cut and shaped into the table's components), and which are not present at all, or not wholly present in the actual object. Finally, a distinction which cuts across all those just drawn is that between the entire matter which constitutes an object (or from which an object comes to be), and the material parts of an object: for instance, my whole human body is to be contrasted with the bodily part that my arm or my leg is.

The second basic question is how Aristotle invokes the notion of matter to begin with. A brief, hand-waving answer to this question is that he conceives material objects -natural 
things or even artefacts- as compound or composite items somehow consisting of form and matter. This applies to tokens as well as types. Thus, Socrates is a particular compound of his human body and his soul (the relevant human form), while the type human is a 'universal' compound (a composite type) consisting of the human body and the human soul. ${ }^{9}$ This Aristotelian hylomorphic view is also extended to items other than particular physical objects and their types. Thus, Aristotle employs hylomorphism to cases of change, to mathematical items, to what he calls 'passions or functions' of the soul, even to essences or forms themselves.

Against this background, several urgent questions arise. Are process-types, such as that of thunder mentioned in section 1, susceptible to this sort of hylomorphic analysis? Even if they are, what (if anything) serves the roles of matter and form in them? In the Posterior Analytics II.1-2 and 8-10, apart from the case of thunder, Aristotle also offers the example of lunar eclipse. Thus, the causal definition, and the definitory conclusion of lunar eclipse have as a counterpart the following scientific demonstration:

Loss of the Sun's light (of type $L$ ) belongs to all cases of screening by the Earth (of type $S)$.

$\underline{\text { Screening by the Earth (of type } S \text { ) belongs to all cases of the Moon (in position } P \text { ). }}$

Light loss (of type $L$ ) belongs to all cases of the Moon (in position $P$ ).

The causal definition of lunar eclipse, then, is as follows:

Lunar eclipse $_{[\mathrm{TYPE}]}={ }_{\text {def }}$ light loss $($ of type $L$ ) belonging to the Moon (in position $P$ ) brought on by screening by the Earth (of type $S$ ).

The definitory conclusion, on the other hand, runs thus:

Lunar eclipse $_{[\mathrm{TYPE}]}=_{\text {def }}$ light loss $($ of type $L$ ) belonging to the Moon (in position $P$ ). 
Are thunder and eclipse, then, to be understood as certain sorts of hylomorphic compound? If so, where, in their definitions, is their form, and more importantly for present purposes, where is their matter?

Let us focus on the question of matter, and its potential presence in such definitions. A more abstract conception of Aristotelian matter is as that which plays the role of a logical subject for a predication, or/and for a predicate to be ascribable to anything. This conception is present, inter alia, in Metaphysics Z.3-5. Thus, for instance, the predicate 'is noisy' or 'involves noise' can be seen as being ascribed to the logical subject 'clouds'. If so, the term 'clouds' can be deemed as the logical matter which underlies 'is noisy', and is necessary for the ascription of 'is noisy' as a predicate-term. For this reason it is necessary to include this logical matter, the term 'clouds', in the scientific definition of thunder, or of other processtypes such as lunar eclipse. In this last case the singular terms 'Moon', 'Earth', and 'Sun' would function in this fashion.

This is, admittedly, a rather 'thin', logico-linguistic or predicative, conception of matter. ${ }^{10}$ A further, cognate notion of matter applicable to process-types such as thunder or eclipse is that of a metaphysical subject (sometimes labelled more formally as 'substratum') for (metaphysical) predication. To see the difference of this notion from logical matter, it is helpful to contrast the predication 'a pale (thing) is walking' with 'a human (who is pale) is walking'. While in the first example there is a logical subject or matter underlying 'is walking', this logical matter does not point to the metaphysical subject underlying the attribute of walking. For 'a pale (thing)' may be picking up any sort of object that is pale, and is walking. In the second example of predication, by contrast, the subject-term latches on a specific type of object, a human, who happens to be (pale and) walking. In this way, then, the term 'clouds' included in the causal definition of thunder (as well as the definitory 
conclusion) functions not only as logical but also as metaphysical matter, what in reality underlies the feature of being noisy (as opposed to the mere predicate 'is noisy').

This, however, is not the whole story. It seems plausible to think that the items which function as logical or metaphysical 'materials' in the ways just adumbrated are also actual material objects or stuffs in a far more robust manner. Thus, for example, clouds are made of droplets of water. Water certainly looks like a material item. So does the fire which is quenched in the clouds. Similarly, the Sun, the Earth, and the Moon, which are mentioned in the scientific definition(s) of the lunar eclipse, are not merely logical or metaphysical matters. Rather, they are celestial bodies. If so, matter is present in the definitions of process-types in a straightforward fashion.

At the same time, though, it is crucial to note that this matter is not shape-less or form-free; it is not 'bare stuff'. Thus, for example, the clouds mentioned in the definition of thunder have the structural features of having fire being quenched in them, and of being noisy. The fire is not present by itself but as a material element which is in the process of being 'cloudily' quenched. Similarly, the celestial bodies picked up by the definition of lunar eclipse are not merely bodies but bodies in certain conditions (e.g. screening other bodies, or being screened by other bodies), located in certain positions, and undergoing certain spatial motions. If it is correct to conceive such features as form-related, it is reasonable to conclude that not only matter but also form are somehow present in the definitions of process-types. Hylomorphism is, therefore, applicable to entities of this sort too, even if in a somewhat attenuated manner.

If this is the case, however, why does Aristotle not make it more explicit in the cases of thunder and eclipse discussed in the Posterior Analytics? This is a difficult question. A plausible, if conjectural, reply is that the level of discussion conducted in this treatise is (what he sometimes calls) 'logical', or too logical (logikôs) to treat these cases as proper 
hylomorphic compounds, or as involving matter in any fully-blown way. Put differently: the type of investigation carried out in his Analytics is not as 'physical' or even 'metaphysical' as that advanced in his Physics, Metaphysics, or the De Anima. In those works hylomorphism is explicitly present, and extends not only to physical (types of) objects but also to less ‘mainstream' cases. An excellent example, at this juncture, would be De Anima I.1. There Aristotle takes up the question of psychic affections and functions, and asks whether they are peculiar to the soul alone, or whether they involve (essentially or necessarily), and are common to, the body too (403a3-5). Psychic affections or functions are to be understood, roughly, as process-types such as getting angry, showing courage, desiring, perceiving, thinking, etc. (403a7-8). Aristotle returns the answer that such psychic process-types are not independent of body but are 'enmattered formulae' (enhuloi logoi; 403a24-5; 403b16-19). If so, he concludes, their definition must make reference to the type of body or matter intrinsic to them. He takes up the example of getting angry, and gives as a schematic definition the formula 'getting angry is (definitionally) a certain sort of change of such and such a body (or bodily part or bodily capacity) brought on by this sort of thing for the sake of that sort of end' (403b25-7).

The first conclusion to be derived from this example is that process-types, too, seem susceptible to Aristotle's hylomorphic analysis: while they are not hylomorphic compound (types of) objects, they are compound (types of) processes. Second, they seem to involve, essentially but not merely necessarily, certain types of matter or body: for matter or body is referred to in their own definition. Again, this matter is accompanied by several 'layers' of form. Hence, for instance, in the schematic definition of getting angry we encounter not simply terms such as 'body', 'bodily part', or 'bodily capacity', but also the term 'a certain sort of change'. It is not, therefore, any and every type of matter which is essential to getting angry but a matter in a certain condition of change, a structural or state-related feature which 
is possible to line up with shape or form. Additionally, this definition mentions the final cause for the sake of which getting angry obtains, or is what it is (heneka toude: 403a27). Because Aristotle systematically lines up, indeed identifies, the final cause with the essence or the formal cause, ${ }^{11}$ this suggests that there is a further form-related item in the definiens of getting angry, the telos for the sake of which this psychic affection is as it is. ${ }^{12}$

\section{Matter in Definitions of Substance-Kinds}

Scientific definitions are not only, not even primarily, of process-types. In Aristotle's view, processes are not the fundamental parts of reality: as suggested in section 2, there are (types of) objects, such as natural things or artefacts, which seem (in some way) more basic than processes. It would be interesting, then, to examine whether, and if so, how the model of scientific definition of types (2) and (3) is extendable to things of this sort. Interestingly, Aristotle himself not only argues for the possibility of this extension to artefact-types and natural substance-kinds, but also develops the Analytics model towards that direction in Metaphysics Z.17 and H.2-4. ${ }^{13}$ On the basis of these examples he presents an explanatory proof about an artefact example as follows (1041a26-8; b5-6):

Having a covering-like structure of a certain sort belongs to being a house.

Being a house belongs to these sorts of bricks, stones, and mortar.

Having a covering-like structure of a certain sort belongs to these sorts of bricks, stones, and mortar.

Following the model of definitions of types (2) and (3) we get:

House $_{[\mathrm{TYPE}]}=_{\text {def }}$ having a covering-like structure of a certain sort belonging to these sorts of bricks, stones, and mortar because of being a house.

It is important to point out that the causal relation in this example is not the same as in the cases of thunder or eclipse. The 'because of' relation in this definition should be understood 
not in terms of efficient causation but in terms of final causation. Thus, the middle term of the corresponding proof, 'being a house', picks up the essence of a house, which in turn is identified with the relevant final cause: being for the sake of sheltering or protecting humans and their belongings from wind, heat, rain, etc. (or some telos along these lines). ${ }^{14}$

Similarly, in the case of Aristotle's example of a natural substance-kind (Z.17, 1041b1-2; 6-7):

Having a certain sort of arrangement belongs to being a human.

Being a human belongs to these types of bones, flesh, etc.

Having a certain sort of arrangement belongs to these types of bones, flesh, etc.

The middle term refers to the essence of the kind human which is the same as the final cause, being for the sake of realising a certain type of rational soul, or living a certain sort of rational life. If so, the causal definition of the substance-kind involves precisely this type of essence which is identical with the relevant telos:

Human $_{[\mathrm{TYPE}]}=_{\text {def }}$ having a certain sort of arrangement belonging to these types of bones, flesh, etc. for the sake of realising a certain type of rational soul, or living a certain sort of rational life.

Aristotle stresses two important theses in Metaphysics Z.17. First, the middle term of proofs such as those just outlined picks up the 'what-it-is-to-be', the essence of an artefact or a natural substance-kind. He remarks, however, that this notion of essence is framed at a 'logical', rather abstract level of metaphysical investigation (1041a28: logikôs). ${ }^{15}$ To make this logical notion more precise and determinate he adds his second thesis: the essence is to be identified with the final, or the efficient (or perhaps even the material?) causes depending on the type of case we are dealing with. In process-types the middle term refers to the efficient cause, whereas in the present case of artefacts or natural substance-kinds it latches on the final cause (1041a27-32; b7-9). It should be noted that this is not only a thesis of 
epistemic or pragmatic interdependence between our practices of definition (as an account of essence) and of demonstration (as an explanatory proof tracking the causal order of the world). It is additionally a thesis of metaphysical interdependence between essence, what fixes the identity of kinds, and robust, real-world causal relations. Hence, essence or form is intrinsically characterised by reference to real-world causal concepts. Conversely, too, efficient or final types of cause also function as identity-fixers of the relevant kind. If so, they too are inextricably dependent upon the notion of essence, form or formal causation. The overall picture, then, is one in which the notions of essence and causation are intrinsically interdependent: they are not specifiable without each other. Indeed, this metaphysical interdependence thesis seems to underwrite the thesis of epistemic interdependence between definition and explanatory proof. Nor is this pair of claims a novelty of the Metaphysics: Aristotle has argued for it in the second book of the Posterior Analytics (mainly II.1-2; II.811).

It seems clear that matter has a prominent place in the scientific definitions of natural substance-kinds too. ${ }^{16}$ Thus, the human kind is defined in terms of not only the form, or/and the final cause that its essence is identical with, but also in terms of certain types of constituent materials, presumably what makes up a functional human body. It is important to re-emphasise, at this juncture, that this matter is not deprived of structural, configurative, or other form-related features. Rather, it is a sort of matter arranged in a specific mode, or a body in a certain state. This is why the term 'functional human body' is a better (if inadequate) description of the sort of matter at issue. ${ }^{17}$

In Metaphysics H.2-4 Aristotle develops this model of defining natural substancekinds in several interesting directions. ${ }^{18}$ One crucial argument maintains that the types of matter mentioned in the definition of (for instance) the human kind are items such as (being a) biped and (being an) animal (1043b10-14). Items of this sort, however, do not seem to 
conform to the hylomorphic model of definition. For being a biped seems to be a differentia, while being an animal is the genus qualified by this differentia to yield the species human. But definitions per genus et differentiam just do not seem to be the same as hylomorphic definitions. It is not necessary to infer from this, though, that Aristotle is mistaken or confused. Elsewhere, he systematically lines up the genus with matter, and the differentia with form, or form-related features (e.g., Z.12, 1038a5-9). This need not be anything more demanding than an analogy. But he may also think that he can somehow subsume genusdifferentia definitions under hylomorphic, scientific definitions of types (2) and (3). This would be an ambitious project. A conjecture about how to pursue it might run as follows. Being biped is, after all, a structural or configurative feature correlative to items such as having a certain sort of arrangement (mentioned in our sample definition of the human kind). This formal sort of feature enforms material substrata such as being an animal. These last are (quasi?) material as they correspond to items such as being a living body. ${ }^{19}$

The extension of the Analytics model to natural substance-kinds raises several questions about the precise implications of Aristotle's hylomorphism. First, there seem to be two main segments present in the definiens: there is a 'dominant' part, the essence or form to be identified with the cause (in the present case the final cause) of the kind human. This is picked up by the explanatory middle term of the corresponding proof. The phrase 'having a certain sort of arrangement belonging to these types of bones, flesh...', by contrast, seems to be describing the material aspect of the kind, picking up items such as flesh, bones, and tissues, their bodily arrangement or structure, etc. In this variant of hylomorphism, the kind human, as becomes obvious from its definiens, is essentially a compound of form (or essence in the dominant sense) -what is described by the defining phrase 'for the sake of realising...' corresponding to the demonstrative middle term- and matter - what is referred to by 'bones, flesh, etc. having a certain sort of arrangement'. 
How are we to understand, however, this dominant notion of essence or form, which is restricted to the referent of the middle term of the corresponding proof, the one picking up the (final) cause? We would expect that in the definition of the kind human the definiens is, in its entirety, an account of the kind's essence. If this is correct, the kind's essence or form should be the real counterpart not just to the middle term 'for the sake of realising...', but to the whole definiens. A suggestion, at this juncture, would be to draw a distinction between a 'quasi-logical', and a 'metaphysical' conception of essence or form. In the 'quasi-logical', abstract conception of essence the whole defining phrase mirrors rather indiscriminately the kind's essence. In the 'metaphysical', concrete, and specific view of essence it is only by reference to robust notions of (final, efficient, or even material) causation that we can specify the kind's essence or form. Hence, even if the definiens includes extra, non-conspicuouslycausal items (such as 'bones, flesh, etc. having a certain sort of arrangement'), these cannot be properly set out as parts of the kind's essence without recourse to the causal segment of the definiens (the middle term 'for the sake of realising...'). Therefore, while having flesh, bones, etc. in a certain sort of arrangement is part of the kind's essence, it cannot stand in its own right, nor is it fundamental as the kind's essence or form. For its nature is not specifiable without mentioning the relevant final cause, being for the sake of realising a certain sort of rational life. The converse, however, is not the case. Importantly, the principle on the basis of which the definiens is dissected in this fashion into dominant and derivative segments is the notion of causation. The dominant part of the essence is what does the basic causing, whereas the derivative part is what gets caused (without being a cause or a principle of the dominant part).

The second difficulty arising from this picture relates to what was labelled the 'material' aspect of the kind's essence, described by the first segment of the definiens, 'bones, flesh, etc. having a certain sort of arrangement'. As pointed out, this phrase refers not 
only to strictly material items, such as this body or these bones, flesh, and tissues, but also to quasi-formal aspects, such as being arranged in a certain structure. If so, the kind human is essentially not just a 'thin' compound of matter and form, but an 'inflated' compound of matter and form, plus some additional form. Isn't this view unnecessarily repetitive (or even babbling) as it includes a double mention of form: first the form belonging to the matter, and then the form or cause which is responsible for the matter's exhibiting the first form ${ }^{20}$ Furthermore, does this view not involve a sort of 'formal over-determination' of the compound kind as the latter seems to have its identity fixed by two separate forms?

This is a crucial issue. To tackle it, one would have, first, to think about the relations of identity and priority as captured by definitions such as the one just offered. It seems plausible to think that the compound kind human is identical with the types of flesh, bones, etc. arranged in a certain structure. By contrast, neither the kind human nor these types of materials so arranged are identifiable with the dominant essence or form, the final cause being for the sake of realising a certain sort of rational life. ${ }^{21}$ Rather, this last item is ontologically prior to both of the former. First, it is prior to the bodily items arranged in this structure: for it makes them functional, and it accounts for their possessing their characteristic structure. These types of flesh, bones, etc. are functional by virtue of realising the relevant final cause described by the middle term present in the definiens. Similarly, the nature of their structure or arrangement is fixed by reference to its being for the sake of realising a certain sort of rational life. Because the dominant essence or form -the final cause in the present case- is prior in this manner to these types of bodily item with this structure, and because these types of bodily item with this structure are identical with the human kind, it follows that the dominant essence or form is ontologically prior to the human kind too. This line of reasoning indicates that the form-related feature of having this sort of arrangement, inherent in the hylomorphic compound, plays a different, less fundamental role than the explanatorily 
basic, dominant essence or form does: for the latter is the causal bedrock which determines the nature of the former (but not conversely). If so, the charge of formal over-determination seems defused.

Nor is it necessary to think that the hylomorphic view of essence or form just outlined is inflationary or repetitive. It is significant that Aristotle's examples of formal features that belong to material items, over and above the form that is identical with the (final or efficient) cause (the one described by the middle term), are based on geometrical shapes, arithmetical ratios, structures, arrangements, configurations, positions etc. ${ }^{22}$ In the important example from Metaphysics H.3 discussed earlier he goes as far as identifying matter with the complex of genus and differentia taken together. He seems, therefore, to be conceiving of formal features such as being arranged in a certain structure, or even being biped as non-causal if taken by themselves. The dominant essence or form, by contrast, what is picked up by the middle term, is irreducibly and fundamentally causal. Moreover, as a (final or efficient) cause, it explains the presence and nature of the non-causal, structural, geometrical, or (to put it figure-atively) 'shapy' formal features belonging to the matter characteristic of the kind. ${ }^{23}$

\section{Matter in Definitions of 'Immediates' or 'Primaries'}

It is important to examine the possible presence and role of matter (if any) in scientific definitions of type (4), which define entities that are explanatorily and causally fundamental in a particular scientific domain. It is not implausible to line up such entities with the essence, form, or cause mentioned in the examples provided in section 3 -the item picked up by the 'dominant' part of the definiens, what corresponds to the demonstrative middle term. ${ }^{24}$ Before tackling this issue, though, it is useful to address a question which is at the heart of the present discussion. It will become clear later that this question applies most acutely to type (4) definitions of fundamental entities. The question is why it is important to 
study whether matter is present in scientific definitions, or not. The first possible approach to this question is exegetical. While it seems incontrovertible that Aristotle takes compounds to be essentially matter-involving, it is unclear whether he thinks that the definition of an essence or form mentions any material items. Indeed, some commentators construe a claim made in Metaphysics Z.10-11as preventing forms or their definitions from having any intrinsic material aspects. For he maintains that a definitory account is (ultimately) of the form alone (1035b33-1036a1; a28-9). If so, how could matter be a part of the basic definitions which set out forms or essences?

In the same chapters, however, Aristotle also argues that certain types of material feature are (essential or necessary?) parts of the form. Thus, he criticises severely Pythagorean and Platonist theorists who discard all matter from the definition of form, and reduce everything to numbers, or other similar 'hyper-formal' entities. More positively, he argues that certain forms, most notably those of natural substance-kinds, are (essentially or necessarily?) 'this sort of formal item in that sort of material item', or 'materials in a certain state'. Thus, for instance, the essence or form of the human kind is not simply to be a certain sort of rational soul (for the sake of realising a specific type of rational life) but also to be constituted of certain bodily parts in certain states (Z.11, 1036a31-b20; b22-32). Similarly, in Metaphysics E.1 natural forms, such as being a human soul, are conceived as involving (essentially or necessarily?) material aspects (1025b30-1026a6). In the same vein, Physics II. 2 takes forms of natural things as being 'not without, but in matter' (194a12-15; b9-13). ${ }^{25}$

The 'hyper-formalist' interpretations would insist, at this point, that in all these claims Aristotle is describing definitions of compounds, not of essences or forms: while it is obvious that the former are matter-involving, it is absurd to think that the latter, too, are somehow intrinsically material. The textual evidence, however, seems overwhelming: Aristotle is interested in the definitions of not only compounds, but also, and primarily, of forms or 
essences. ${ }^{26}$ Further, he takes definitions of forms as (essentially or necessarily?) matterinvolving. A tentative but attractive strategy with which to reconcile this thesis of enmatterment with the previous claim that definition is of the form alone would run as follows. Clearly, the definition of form should not mention token material items or bodily parts, such as my nasal matter or your human body. Nor should it refer to specific types of material items, such as exercised muscles, or eyes with acute, 20/20 eye-sight. If this is correct, Aristotle's position that the basic definitions are of form and form alone would filter out only these types of matter. There is, however, nothing which would prevent more abstract material features, or material ways of being, from being present in the essence of a form, and mentioned in its definition. Hence, for instance, the essence being human (or being a human soul realising a specific sort of rational life) may include items such as being constituted from, or incorporated in, a particular type of body with a certain structure, being made of determinate types of bodily parts in certain conditions or states, etc. ${ }^{27}$ This is also an argument which underpins the possibility of there being certain types of matter in the form itself, a possibility which Aristotle himself seems to countenance when speaking of the 'matter of the form' (Metaphysics 4.24, 1023b1-2; cf. Phys. II.9, 200b7-8).

The second way in which to address the question of why it is important to scrutinise the presence of matter in a definition is philosophical. First, it is worth observing that even if it is agreed that Aristotle takes matter to be an intrinsic part not only of compounds but also of forms, it does not follow that matter is essentially involved in a form. For the link between form and matter may be strong yet not essential. Thus, a form may be only necessarily but not essentially dependent on matter. ${ }^{28}$ This result signals a return to the initial questions raised in the beginning of section 4 about whether, and if so, how matter is present in the definition of form or essence, a paradigmatically 'immediate' or 'primary' entity. These questions become urgent in the case of form or essence precisely because it is an immediate 
or primary entity. For other items in the ontology, such as process-types, artefact-types, or natural substance-kinds, are ultimately dependent for their nature, and their necessary features on their essence or form. The latter is primary or immediate in that it is the primary substance, cause, and principle of the former. Correspondingly, the definitions of the dependent entities are grounded on the definition of the primary and immediate entity that their essence or form is. It follows that the crucial question is, and has been all along, whether, and if so, in what way matter is present in the definition of form or essence. For, even if matter is mentioned in the definitions of processes, artefacts, or substance-kinds, its presence would be metaphysically dispensable unless it served a central role in the definitions of the relevant forms too.

Assuming that matter can be, and indeed is, mentioned in the definition of the form, what is the significance of its presence? A brief reply would be that the material aspects integral to the form's essence are there to function as an explanans, or as a ground, for essential and necessary material features, bodily parts, or other matter-like items which are characteristic of compounds. Thus, for instance, essential material aspects within the human form would account for the material nature of the compound human kind. In the example provided in section 3 the definition of the kind includes the term 'flesh, bones, etc. in a certain arrangement': an essentially enmattered form would explain, inter alia, the mention of this sort of materials.

A further important role of the material aspects of a form's essence would be to underwrite claims of hypothetical necessity. Aristotle argues that it is necessary that there exist certain types of matter, if the form (or essence) is to exist. It is, however, because of the form being as it is, that the relevant (range of) types of matter are as they are, and are necessarily present for the form's embodiment. For example, while it is necessary that a certain type of metal exist if the form of the saw (e.g., the relevant capacity for cutting) is to 
exist, the nature of this sort of metallic matter is determined by the (essence of the) form, being capable to cut in the relevant manner. ${ }^{29}$ How could the saw's form ground the nature of the corresponding matter, and underpin its hypothetical necessity if it did not essentially involve some appropriate material aspects? Necessity claims of this sort are notoriously difficult to sustain if the form does not include an appropriately material grounding base. The alternative of taking claims of hypothetical necessity as primitive or crude metaphysical facts seems unattractive.

An additional point, indicative of the role of matter within the form's essence, is the way in which material items could explain the presence of necessary change-related features characteristic of compounds. This point is systematically stressed by Aristotle in his Physics and Metaphysics. ${ }^{30}$ It is based on Aristotle's view of the necessity of matter for explaining all types of change. Suppose, to use an artefact example, that the explanandum is the capacity of a gymnastics 'Swiss-ball' to roll in the certain way it does (locomotion), or to resist bodily weight, and to modify, temporarily lose, and regain its shape due to this capacity for weightresistance (alteration). If the explanans were simply the abstract, geometrical formal feature of being spherical, or/and the telic feature of being capable of facilitating core and abdominal exercise in the Swiss-ball sort of way, it could prove unable to ground the specific changerelated features of the Swiss-ball. For these features depend on material aspects such as being made of a certain type of rubber with specific characteristics, being inflated with air of a particular range of atmospheric pressure, being placed on surfaces covered with certain sorts of materials, etc. Without essentially involving such material aspects the form could not, arguably, ground the relevant necessary capacities for change of the compound Swiss-ball. Apart from this manifold of explanatory or grounding roles, however, there is a deeper motivation for examining whether, and (if so) how matter is present in the form's essence. This inquiry is fuelled by worries about the unity of natural compounds. Aristotle 
insists that natural, compound substance-kinds are unified in an essential, intrinsic fashion. He contrasts this sort of unity with the heap-like unity which obtains in cases of what he calls 'accidental compounds' such as the pale human. In this last case, being pale and being human are essentially independent of each other. The corresponding accidental compound, then, is understood as a complex consisting of two entities that are mutually different in nature. By contrast, while the compound substance-kind human involves a certain form being metaphysically predicated of some matter, yet the unity between these two items is not heaplike. Nor is the substance-kind an accidental compound. Because Aristotle argues that the source of this essential or intrinsic unity is to be found in the (dominant) essence or form -the (final) cause picked up by the middle term present in our sample definition- it is important to understand in what way, or in virtue of what the essence, form, or cause can carry through this unifying task. ${ }^{31}$

There are three general lines of approaching this last question. First, it may be argued, form and matter are two independent conjuncts, which somehow, by a very special, profound way of being put together, give rise to the compound's unity. In this view, because the form is radically different from matter, its nature is conceived in a sort of 'spiritualist' manner: natural form is essentially immaterial. ${ }^{32}$ A crucial problem for this view is that it seems to render natural forms too similar to mathematical forms, which Aristotle takes as abstractions in thought. How, then, could this matter-free sort of form account for the presence of perceptible matter in natural compounds? Or how could it ground their characteristic capacities for change, capacities which presuppose an intimate dependence on matter? Moreover, how could it sustain claims of hypothetical necessity? The spiritualist would reply that, while no mention of matter is made in the form's definition, certain other items mentioned in it imply, even necessarily imply, that forms are enmattered -perhaps even in the specific types of matter that they are characteristically enmattered in. Even so, however, there 
remain questions about how to underpin the entailment, and the necessity involved in this last claim.

Second, some hold that the compound's unity is basic, not to be reduced to the unifying function of form, or to the profound union between form and matter. Not only are form and matter grasped by some sort of thought-abstraction from the compound; they are themselves abstractions in thought. If so, there is no need for any special way of putting together form and matter to generate the compound's unity: for unity is already present in the compound in virtue of itself. In this view, the usual strategy for setting out the form's nature is to follow a 'functionalist' line. ${ }^{33}$ Natural compounds, and perhaps even their forms insofar as they are not abstractions, are essentially matter-involving. There are, however, different types of matter: a 'malevolent', remote, bulky and constituent matter (e.g., the elements; or bones, flesh, etc.); and a 'functional', purified, proximate matter, sometimes identifiable with, or definable in terms of, the form. It is this latter matter which is part of the form's definition. Indeed, its nature as functional matter is fully specifiable only in terms of form. In this view, then, the form is both essentially enmattered, and prior to matter. The functionalist line faces two main challenges. First, it may be objected that functional matter is simply too abstract to account for the nature of compounds, their material character, and their capacities for locomotion, alteration, growth, etc. Second, one may argue that the functionalist's form could not be prior to the compound if the compound's unity is fundamental. While Aristotle holds that the form accounts for what the compound is, and makes it one definite type of thing, the functionalist gets Aristotle's explanatory and ontological priority arrows the wrong way around.

Third, we may consider natural form itself as essentially matter-involving. In one version of this view, the material aspects included in the form's content are not reducible to, or fully specifiable in terms of formal aspects, functional or telic items, or mere "potentialities 
for change'. Moreover, the formal and material aspects intrinsic to natural form are essentially interdependent on each other in a non-decomposable manner. This view avoids a crude form of materialism: for it does not render natural form reducible to matter. It also denies the identification of natural form with mathematical, Platonist, spiritualist, or functionalist form: ${ }^{34}$ for the material aspects present in the form are not reducible to, or fully definable in terms of, its formal aspects. Rather, the formal and material aspects within the form's own essence cannot be defined without each other. The urgent question that this view has to address is how an essentially matter-involving form could be prior to matter. A rough reply to this question would be that, while a form cannot be prior to its own material aspects, yet it can be prior to the token-materials of (particular) compound substances, and the specific type-matters of (universal) compound substance-kinds. ${ }^{35}$

\section{Further Questions}

The discussion of this last issue leads naturally to a crucial difficulty which besets Aristotelian hylomorphism, and challenges its limits. One could reply to the question of whether the essence or form itself is essentially matter- or/and form-involving, or not by holding simply that the question is either ill-formed or nonsensical. For, one would argue, the matter-form distinction is not intended to apply to the form itself, but only to the compounds (tokens or types) constituted from matter and form. This objector could concede that Aristotle deploys, without hesitation, a hylomorphic style of analysis in treating natural or artefact forms themselves, the 'functions and affections' of the soul, or even more remote items such as mathematical entities. Thus, apart from the examples adduced in the previous sections, he also holds that mathematical forms such as being circular or being triangular contain an 'intelligible' sort of matter (e.g., being made of lines, or being continuous) in addition to their formal aspects (Metaph. Z.10, 1036a9-12; Z.11, 1036a31-b20; b32-1037a5). It does not, 
however, follow from this (the objector would argue) that hylomorphism applies to such cases too in any fully-blown fashion. Rather, the objector would counter-propose that such cases are hylomorphic only by analogy; or that the hylomorphic style of analysis is merely a heuristic device deployed solely as a starting-point for our inquiries into items of this sort. At any rate, the objector would conclude, the hylomorphic approach need not entail that anything other than (token or type) compound objects are literally hylomorphic in any weighty sense. A promising rebuttal to this objection would have as its starting-point the arguments outlined in section 4 about the explanatory, grounding, and unifying concerns of an Aristotelian hylomorphic view which is global in more than a merely analogical or metaphorical fashion.

A second challenge to a global version of Aristotelian hylomorphism would seek to undermine the question raised in section 4 about the possibility and the mode of the matter's presence in the essence of a form, or its mention in a form's definition. For, the challenge would suggest, this question itself presupposes the incoherent idea that there is an essence of an essence, or a form of a form, or a definition of a definition. Essences, forms, and their definitions, however, just carry through the essence-related, the en-forming, and the defining tasks. They are not themselves subjects to, or patients in, such tasks. If so, it does not make any sense to ask about the essence of an essence, the form of a form, or the definition of a definiens which picks up a form or essence. And even if it did make sense to pose this question, any sort of answer which seeks to set out the alleged essences, forms, or definitions would be self-defeating as it would generate an infinite regress, or a vicious circle. ${ }^{36}$

This is a serious line of objection. To come to grips with it, it is necessary to explore what kind of entity the essence or the form itself is. Already in the Categories Aristotle makes a distinction between particular objects or types of object, on the one hand, and essences or forms, on the other. Hence, he speaks of particular or individual substances, 
token-objects such as Socrates (or this human) or Bucephalus (this horse), their species or genera -what he labels 'secondary substances'- type-objects such as the species human, or the genus animal, and (less conspicuously in the Categories) the what-it-is of token- or typeobjects. This last item seems cognate with the 'what-it-is-to-be- $x$ ', or $x$ 's essence, as set out in the Metaphysics. Aristotle argues that within the class of secondary substances species enjoy some sort of priority over genera as they are the proper answers to 'what is it?' questions asked about particular substances. Thus, 'a human' is a more determinate, and so a better answer to the question 'what is Socrates?' than 'an animal' is. Following this let us focus on species alone as paradigmatic cases of type-objects. ${ }^{37}$

In one possible view of Aristotle's notion of $x$ 's what-it-is or essence, it is nothing other than these type-objects, species such as (the) human (type/kind) or (the) horse (type/kind). Alternatively, one may adopt a view of essence as the 'species-form', something like the 'species understood intensionally'. Yet another position, motivated by the idea that the relation between an individual substance and its essence must be identity, argues that an essence is individual, peculiar to each particular substance it is the essence of. This last position would saddle Aristotle with a view of essence as a particularised substance property or feature, a sort of essential trope. All these alternatives seem problematic: for they either identify an essence with a type-object, something which clashes with Aristotle's claims; ${ }^{38}$ or they employ the obscure concept of the species understood intensionally; or they set out the notion of essence by reference to (particularised) attributes, features, or properties, something which is difficult to reconcile with Aristotle's distinction between essence and mere attributes (or even propria; see, for example, Topics I.5); or, quite generally, they conceive essence as a universal-like item, a position which disagrees with Aristotle's argument against the identification of primary substances with universals (Metaphysics Z.13-16). 
An attractive possibility would be to take seriously Aristotle's phraseology of 'whatit-is' in the Categories, or 'what-it-is-to-be- $x$ ' as well as 'being $x$ ' in the Topics, the Analytics, and most importantly the Metaphysics. ${ }^{39}$ What this terminology suggests is that essences or forms are neither token-objects (particulars like Socrates), nor type-objects (species like the human kind), nor universal-like items such as features, attributes, or properties (like justice, humanity, or sphericity). Rather, essences or forms seem to be (essential) ways or modes of being for the token- or type-objects they are the essences of. ${ }^{40}$ Thus, for instance, the essence of Socrates, or the essence of the type human is to be human, or being human. Ways or modes of being are, arguably, the ontological counterparts to open sentences such as '_ is $F^{\prime}$

Here are some advantages of this view. First, it is sensitive to the deep, categorial difference that seems to obtain between token- or type-objects, on the one hand, and their essences, on the other. Second, because a way of being clearly is necessarily dependent for its existence on the existence of (some or other) token- or type-objects for which it is a way of being, this conception of essence or form avoids implausible, Platonist versions of essentialism: for essences (unlike Platonist Forms) cannot exist without any token- or typeobjects existing. Third, understanding essence in terms of a way or mode of being is neither circular nor tautological. The concept of a way of being is general enough to be distinct from that of an essence. For a way of being is not sufficient, by itself, to mark out an essence from a non-essence. After all, there are many ways of being -being pale, being sun-tanned, being sun-burnt, etc.- which may be ways for Socrates or for (members of) the human-type to be without being essential ways of being for them. Because ways of being seem to be the ontological correlates of open sentences, the essentiality of a way of being can be conceived of as the real counterpart to an adverbial qualification or copula-modifier such as 'essentially': to be Socrates or to be (a member of) the human kind is to be essentially human. 
Fourth, this view also allows for Aristotelian notions such as potentiality or actuality to be the real-world parallels to corresponding copula-modifiers such as 'potentially/actually', 'in potentiality/actuality', or 'in respect of potential/actual being'. Thus, for instance, to be the matter of a house -the house-buildable bricks, stones, and mortar-is to be potentially a house. Or to be an actual house, one that exemplifies the form and the final cause of being a house, is for the bricks, stones, and mortar to be actually arranged as a covering for the sake of protection of humans and their belongings from wind, heat, and rain (or something along these lines).

Most importantly, though, this view respects our intuition that an essence is ontologically prior to the items it is the essence of: for it makes the latter what they are but not conversely. This asymmetric relation of priority cannot be preserved by views which identify a token- or type-object with its essence. For this sort of identity (an equivalence relation) would be symmetric, while the ontological priority relation is asymmetric, and no relation can be both symmetric and asymmetric (in the same way or sense). Understanding essence as a way of being emphasises at the outset the categorial distinctness, and so the nonidentity between an essence and the relevant essence-bearer. ${ }^{41}$ If so, it accommodates (or at least does not disregard) the intuitive idea that an essence is ontologically prior to (but not identical with) the token- or type-object it is the essence of.

In the light of this the apparent absurdity of the notion of the essence of an essence, or the form of a form, can be dispelled as follows. In the definition of a type-object

(T) The $F($ type $)=_{\text {def }}$ being $F$, the definiens-term 'being $F$ ' picks up the essence, the way of being essential to the type $F$. The relation between this essence and the type is not identity. Rather, the essence is prior to the type: for being $F$ is what makes the $F$ the type it is. The non-identity relation can be read off immediately from (T) as the $F$ and being $F$ are categorially diverse items. Further, the 
priority relation is based on the essence's role of making the type what it is but not conversely. This asymmetric relation can be filled out, and underwritten by the robust, realworld causal relations that obtain between the essence and the type. As noted in section 3, the 'dominant' part of the definiens, what corresponds to the middle term of proofs, picks up an efficient or a final (or even a material?) cause, depending on the sort of case at issue. While this fundamental item does the causing, and fixes the identity of the type, it itself is not caused, or made what it is by the type. It does not follow from these points, however, that we cannot give a definition of a type which is, or involves an identity statement. Indeed, nothing prevents us from recasting $(\mathrm{T})$ as follows:

$\left(\mathrm{T}^{\prime}\right)$ The $F($ type $)=$ the type whose essence is being $F$.

For it seems incontrovertible that the type $F$ is identical with the type whose essential way of being is to be $F$.

The definition of an essence or a form, by contrast, which picks up the essence of an essence, or the form of a form runs as follows:

(ES) Being $F=$ being $X Y Z$

Here there is no priority relation of the definiens over the definiendum. First, from a logicogrammatical viewpoint, it is clear that the expressions 'being $F$ ' and 'being $X Y Z$ ' are intended to pick up ways of being. Because both being $F$ and being $X Y Z$ are ways of being, the relation between them can be strict identity. Second, this relation is indeed identity, and not priority. For being $X Y Z$ is not the way of being that makes being $F$ what it is. Nor is being $X Y Z$ the essence that being $F$ has. Rather, being $X Y Z$ is the essence that being $F$ is identical with. Whereas in (T) the $F$ type is not identical with but has the essence being $F$ (as being $F$ makes it what it is but not conversely), in (ES) being $F$ does not have but is (identical with) the essence being $X Y Z$. The deeper reason for this basic identity is that there is no prior cause or principle which accounts for the nature of being $F$ : for it is a fundamental, 'primary', or 
'immediate' entity which serves as the cause and principle of other items (within a certain domain) without having a cause for its own being or nature. ${ }^{42}$

If this is correct, there is no absurdity in the notion of the essence of an essence, or the form of a form. For what definitions such as (ES) aim to achieve is not to describe anything metaphysically or causally more basic than the essence or form being $F$, or to ascribe to it any prior essence or form that it has. Rather, their goal is to set out or unpack the content of being $F$ itself, the essence or form that it is (identical with). There is no ontological, metaphysical, or causal priority of the definiens over the definiendum posited by (ES): for there is nothing prior to the definiendum in any of these substantive ways. It is certainly possible, though, that there is an epistemic relation of priority of being $X Y Z$ over being $F$. For being $X Y Z$ may be a clearer, more elaborate, or more precise way in which knowers such as ourselves grasp what is involved in being $F$. Or being $X Y Z$ may be important for learners of a scientific discipline. In the example of being a unit, provided in section 1, the demonstrative science of numbertheory assumes the existence of being a unit, and posits its essence: being indivisible in quantity. ${ }^{43}$ On the basis of the definiens of this type (4) definition one can grasp the principle that being a unit is, and go on to learn number-theory: for one can (explicitly or implicitly) refer the proofs of this demonstrative discipline back to this basic definition. It is not the case, however, that one could prove the existence, or establish the essence of being a unit on the basis of the definiens being indivisible in quantity. For the definition of being a unit is an indemonstrable posit which describes nothing prior to, but only what is identical with, being a unit.

There is a final problem arising from the picture of essence or form as essentially (but not merely necessarily) matter-involving. Suppose that it is correct to think that hylomorphism applies to essences or forms in more than a merely metaphorical fashion. Suppose also that the 'essence of an essence' or 'form of a form' objection is a pseudo- 
problem: for essences or forms are to be defined by way of definitions such as (ES) without any danger of infinite regress, or vicious circularity. Even so, however, if essences or forms are essentially matter-involving, they seem to collapse into a sort of hylomorphic compound. For, if they are intrinsically hylomorphic, what is their difference from, and what does their 'essence-' or 'form-hood' consist in by contrast to, essentially material compounds such as the natural substance-kinds discussed in section 3 ?

It is tempting to reply that essences or forms which are essentially matter-involving do not turn out to be a glorified sort of hylomorphic (token- or type-) compound. Their difference from such compounds is twofold. First, the mode of involvement of matter in essences or forms is different from that in the case of compounds. Thus, for instance, the token-matter included in particular compounds such as Socrates or Bucephalus is involved in them in a non-essential, or merely accidental manner. For these token-compounds are (essentially) what they are independently of their token-matter as they could replace or lose this matter (gradually, or even perhaps entirely and abruptly) while retaining their nature. Socrates would still be a human even if he replaced (some or all of) his bodily cells provided that he is constituted by some or other human cells. Similarly, the specific type-matters belonging to type-compounds are involved only accidentally in them: for example, the type human is essentially independent of types of matter such as skin of pale complexion, or nose of concave shape. The way of involvement of the relevant material features in an essence or form, by contrast, is essential. Hence, being made of a certain type of body with a specific structure, or having bodily parts or organs in certain states or conditions are integral to the nature of the essence or form being human. Further, if we follow the third view of essential enmatterment outlined in the last paragraph of section 4, material features of this sort are involved essentially in an even stronger fashion: for they, and the corresponding formal or 
telic aspects of the essence or form are essentially interdependent in an inextricable, indissoluble, and entirely unified way.

Second, an essentially matter-involving essence or form is different from (token- or type-) compounds in that the material items or entities involved in it are categorially different from those inherent in compounds. As suggested earlier, whereas compounds are token- or type-objects which include token- or type-materials, an essence or form is a way or mode of being which involves essentially material (as well as formal and telic) ways or modes of being. The essence or form being human does not involve essentially my token bodily parts, nor the type well-exercised biceps. Rather, its material nature includes items such as being constituted from a certain sort of flesh, bones, etc. with a specific structure, or being composed of bodily parts of certain types in determinate conditions, states, or functions.

It could be counter-objected, at this juncture, that this view makes the definition of natural substance-kinds materially over-determined, and babbling. In section 3 these twin problems were discussed in connection with the apparently 'double' formal nature of natural substance-kinds. In the present case, though, the definition of a substance-kind such as human seems to have 'double' matters: the type-matter which is involved in the first segment of its definiens (e.g., flesh, bones etc. with a certain arrangement) plus the material way of being involved in the unpacked 'dominant' part of its definiens (e.g., being a rational soul, or being for the sake of realising a certain sort of rational life being constituted from a certain type of body thus-and-so arranged). Does this result not make substance-kinds materially overdetermined? Does it not render their definitory formulae unnecessarily repetitive? ${ }^{44}$ And, more vividly, if the essence of the human kind, and presumably of a member of this kind, too, involves two matters, or two bodies, why does a human not weigh double as much as he or she actually does? 
A tentative answer to these worries would run along the following lines. A substancekind with an essentially matter-involving form is not materially over-determined: for the material aspects of its form are responsible for the nature of the essential types of matter characteristic of the kind. The former are the bedrock of determination as they make the latter what they are but not conversely. In effect, the essential material character of the substancekind is ultimately fixed by the material aspects of the form alone but not by way of collaboration between 'two matters'. If this is correct, the definition of the substance-kind is not babbling or repetitive: for there is no multiple mention of the same type of material entity. This brings us to a possible line of reply to the 'double weight' problem. It is true that in certain views of essential enmatterment (e.g., the third view sketched at the end of section 4) the material aspects integral to form are not 'purified', solely functional, or telic. Rather, they are robust, 'bulky' or 'gritty' material ways of being. Even so, however, being robust, being bulky, or being 'gritty' just is not the type of material entity which could weigh anything. It is not any material way of being of this sort but only the bulky, 'gritty', or heavy physical object, a material compound itself (a member of a specific substance-kind) which has weight.

\section{Notes}

${ }^{1}$ I am indebted to Simona Aimar, Thomas Ainsworth, David Charles, Alan Code, James Lennox, and the other participants in the seminar, and the related conference, on Aristotle's hylomorphism, which took place in Oxford in 2012, for their invaluable questions, comments, contributions, and objections.

${ }^{2}$ This fourfold distinction is based on what seems the most attractive interpretation of this chapter. See Charles D., Aristotle on Meaning and Essence, Oxford, OUP, 2000, pp. 23-48; for alternative readings see Ross W.D., Aristotle's Prior and Posterior Analytics, Oxford, 
OUP, 1949, pp. 634-636; Bolton R., 'Essentialism and Semantic Theory in Aristotle:

Posterior Analytics II.7-10', Philosophical Review 85, 1976, pp. 514-544.

${ }^{3}$ The phrase $\hat{e}$ logos heteros onomatôdês at APo II.10, 93b30-31, is difficult to construe. The most literal understanding is to take it as a disjunct linked to onoma at b30. Thus, a definiendum in a semantic definition is either a name (term), or an account which is different from a single, monolectic, name (term). This would be a phrase which consists of more than one name/word. Yet this periphrastic phrase is name-like as it can be the name of a (kind of) thing, or at least can be stipulated as such. Alternatively, Aristotle may be offering $\hat{e}$ logos heteros onomatôdês as a disjunct which is linked not to onoma but to (the first) logos at b30: the first type of definition is either an account of what a name signifies, or a different namelike account (i.e. name-like definition). In this last construal, Aristotle is envisaging what modern philosophers, starting with Locke, call 'nominal' definitions. This last view does not seem plausible. If we compare this passage with Metaphysics Z.4, 1030a7-16, we see that Aristotle invokes accounts of what a name signifies, if there is such a single, one-word name. If, however, there is no such name, there can still be a similar semantic definition: in this case the signification of a simple (periphrastic) account would be given in terms of another, more elaborate and more precise (periphrastic) account. Thus, for instance, while there is no single name for the compound pale man, there is a simple account, 'pale man' (cf. 1029b271030a11). This haplous logos of Metaph. Z.4 seems parallel to the onomatôdês logos of APo II.10. Its definiens would be a more articulated and precise logos, perhaps something like 'being pale belonging to a man' (1030a14-16: hoti tode tôide huparchei).

${ }^{4}$ Of these two definitions the first may be taken as immediately implying that there is indeed something, an existent (kind of) thing, which is signified by the term 'triangle'. This is so if 'to signify' implies 'to refer to something in reality'. The second sort of definition is less committal as to existential import: for claiming that ' $t$ ' signifies the same as ' $r$ ' does not 
require that either term signify any existent. For the relation of a name's or a term's signifying the same as another name or term, cf. Metaph. Z.4, 1030a7-9; 14-17; 1030b7-10. Regardless of our preferred formulation, it seems reasonable that semantic definitions should be understood as involving a suppressed clause such as 'if the definiendum-term signifies anything existent at all', or 'if such a thing corresponding to the definiendum-term exists'. ${ }^{5}$ For a plausible suggestion as to how semantic definitions are important for scientific inquiry, without being (strictly speaking) scientific, see David Charles's 'springboard' view: Aristotle on Meaning, pp. 35-36.

${ }^{6}$ The subscript '[TYPE]' suggests that we are interested in defining the type of phenomenon or process that thunder is. We are not, then, defining a token occurrence of thunder. It is true, though, that if particular occurrences of thunder are essentially tokens of the type process, this definition applies to them too. This last claim, however, stands in need of further argument (for an attempt, see Williams S. G. \& Charles D., 'Essence, Modality and the Master Craftsman' in Feser Ed. (ed.), Aristotle on Method and Metaphysics, PalgraveMacMillan, 2013, esp. $\S \S 3-6)$. The symbol ' $=$ def' is to be understood as 'defined as'; it does not necessarily imply strict numerical identity between the definiens and the definiendum but it may do so depending on the case in view. This last issue will be discussed briefly in section 5.

${ }^{7}$ These differences between semantic definitions and definitory conclusions are also important in answering the question of why in his summary of the types of definition towards the end of APo II.10 Aristotle does not mention semantic definitions but only causal definitions, definitory conclusions, and indemonstrable suppositions of what-it-is. Briefly, in that summary he focuses on definitions of things, not of terms; he is interested in definitions that have strong links to scientific demonstrations; and he aims at showing how grasping such definitions relates to our proper knowledge of the (kinds of) things there are. 
${ }^{8}$ A further important point which rests on the notion of causation, and its link to scientific proof concerns the interrelations between causal definitions and definitory conclusions. It seems clear that the definiens of a type (3) definition such as

Thunder $_{[\mathrm{TYPE}]}=_{\mathrm{def}}$ a noise (of type $N$ ) belonging to (or: in) the clouds (of type $C$ ), is an integral part of the definiens in the corresponding type (2) definition

Thunder $_{[\text {TYPE] }}=_{\text {def }}$ noise (of type $N$ ) in the clouds (of type $C$ ) brought on by fire being quenched (of type $Q$ ).

Thus, causal definitions seem somehow to subsume definitory conclusions. The principle of subsumption seems to be the relation between what does the causing, and what gets caused. Thus, for instance, because the definitory conclusion describes what gets caused (the process of thunder, or of noise's belonging to the clouds), it can be incorporated in the causal definition, which describes what does the causing (fire's being quenched). The converse, presumably, is not the case. This point need not be taken as a claim strictly about causation (or even efficient causation, given our present example). There is an equally basic, counterpart claim which encapsulates important theses about the essence or nature of things. Thus, thunder, or the noise's belonging to the clouds, is the thing for which there is a (prior) essence or nature, whereas the quenching of fire is this essence or nature which grounds the existence and being (as well as the necessary features) of the process that thunder is. For this reason the definitory conclusion can be nested in the causal definition: for the latter describes the nature or essence of the former (but not conversely).

${ }^{9}$ The claim that not only particular substances (tokens) but also universal types (mainly species) are hylomorphic compounds is most prominently present at Metaph. Z.10, 1035b2731. 
${ }^{10}$ This becomes clearer once we compare this 'logical' matter with the examples of matter provided in the opening paragraph of section 2.

${ }^{11}$ See, for instance, Physics II.7, 198a24-7.

${ }^{12}$ A proper study of Aristotle's view of process-types, of their definitions, and of the role of matter in these definitions would have to examine his claims and arguments in the rest of the De Anima about psychic phenomena such as nutrition, perception, desire, and thinking. Further, it would have to treat some of the psychic 'functions and affections' discussed in the Parva Naturalia, such as sleeping, dreaming, and respiration. Finally, and most importantly, it would have to deal with the biological treatises, and the way in which life-functions (and life-affections) are understood, and the presence and role of matter in their definitions. All these important issues lie well beyond the scope of the present study.

${ }^{13}$ That Aristotle operates against the background of the Analytics model is clear from his reference to the celebrated examples of thunder and eclipse (Metaph. Z.17, 1041a15-6; 24-5). It should also be emphasised that Aristotle's interest in $Z .17$ is not only in the role of substance and essence as a cause and a principle. Nor is he taking up merely the relation between such causes and principles, on the one hand, and explanation and demonstration, on the other. He is not, therefore, disregarding the link of demonstration to definition, on which he insisted in the Analytics. Rather, definition, as an account of essence and form, has a similar important role to play in this chapter too: see 1041b1-2; 7-9. For a different view see Bolton R., 'Biology and Metaphysics in Aristotle' in Lennox J. G. \& Bolton R. (eds.), Being, Nature, and Life in Aristotle: Essays in Honor of Allan Gotthelf, CUP, Cambridge, 2010, pp. $30-55$.

${ }^{14}$ For an interesting and admirably lucid view which denies that final causes can be picked up by demonstrative middle terms, see Leunissen M., Explanation and Teleology in Aristotle's 
Science of Nature, CUP, Cambridge, 2010, pp. 7-8; cf. pp. 13-15; 20-21; 135-136; 179-180; 183-189; 200-201; 211.

${ }^{15}$ This remark should be compared with the claim made towards the end of section 2 about the level of inquiry advanced in the Posterior Analytics.

${ }^{16}$ The definitions of artefact-types, too, mention matter but these can be put to the side for present purposes.

${ }^{17}$ There is an issue of circularity at this point. It would not be correct to define the kind human in terms of a sort of matter which is specified as 'human' matter: for such a definition would be (viciously) circular. Presumably, a fully worked-out, scientific definition would possess the resources to avoid this sort of circularity. The terms 'a certain sort of arrangement', 'functional human body', etc. work as dummy or 'gappy' terms, to be filled in appropriately on the basis of fully worked-out, scientific definitions of types (2) and (3). ${ }^{18}$ See, for example, Metaph. H.2, 1043a4-21; H.3, 1043b10-14; H.4, 1044a32-b20.

${ }^{19}$ While this issue is important, it lies outside the scope of the present study. But it is worth mentioning as it suggests that there may be a wider, or non-uniform Aristotelian understanding of the nature of scientific definition. Aristotle may have remained undecided or non-committal as to whether hylomorphism provides the single model of scientific definition, or whether there are several further definitional models, by genus and differentia, by division and collection, etc. Moreover, if he thought that there are multiple models of scientific definition, it is unclear whether he held that one amongst them is fundamental, or whether they stand on a par, as it were, alongside each other.

${ }^{20}$ Aristotle seems to be expressing a similar sort of worry about 'babbling' definitions (insofar as this worry applies to the material items of the definiens) in the discussion of his favourite example of a hylomorphic compound, the snub-nose, being snub-nosed, or 
snubness/being snub: see. Metaph. Z.5, 1030b28-1031a1; Sophistici Elenchi 13, 173b1-11; 31,181b35-182a6.

${ }^{21}$ That the relevant type(s) are not identical with the dominant essence, the form or (final) cause being for the sake of realising a certain sort of rational life, can be established on general, categorial grounds too, if it is correct to think that an essence -the what-it-is-to-beis a way or mode of being. For in that case, because the essence is a way of being, it cannot be identical to any type-object such as the human type, or the type of matter arranged in a certain structure. This issue will be taken up in section 5 .

${ }^{22}$ Aristotle offers several cases of such merely 'shapy' formal features belonging to a kind's matter at Metaph. H.2, 1043a2-12.

${ }^{23}$ For a more detailed treatment of this problem, and of the proposed solution, see Peramatzis M., Priority in Aristotle's Metaphysics, OUP, Oxford, 2011, part I, esp. chapter 7.

${ }^{24}$ It is worth comparing this claim with the position of Posterior Analytics II.8-9 about ‘immediates' (93a3-6; 93b21-5). That an essence or form is a 'primary', 'per se', or 'immediate' being, i.e. a fundamental entity which is a cause of other things' being, without anything else being its own cause of being, is clear from Metaph. Z.6, 1031a28-30; b11-15; 1032a4-6; Z.11, 1037a33-b7.

${ }^{25}$ Even the discussion of De Anima I.1 about psychic functions and affections can be plausibly taken as covering formal items too, without being restricted to compound kinds alone. Thus, psychic 'doings or sufferings', such as getting angry, can be thought of as instances of, or correlates to, not only compound kinds, but also essences or forms. Hence, Aristotle writes that such psychic items are logoi, i.e. formulae or form-like entities. Furthermore, they are enhuloi as they involve (essentially or necessarily?) matter, bodily parts, or material capacities (403a25). 
${ }^{26}$ Thus, Metaph. Z.11, 1036a26-7 (the governing question is what the parts of eidos are); $1036 \mathrm{~b} 2$ (the eidos of circle); b3 (the eidos of human); b5 (parts of the eidos and the logos); E.1, 1025b28-30 (what is investigated is the ti ên einai and the logos); b30-1 (our question is about the ti esti); 1026a5-6 (natural forms, such as souls, are dependent on matter); Phys. II.2, 194a12-15 (natural forms are like simotês, snubness, or being snub; Aristotle does not use the term to simon, which would be the analogue to a compound, but the term for being snub or snubness, which is a form-related feature); 194b9-13 (the question is about the eidos and the ti estin); and De Anima I.1, 403a25 (psychic functions and affections are entities which are logoi: formulae or forms; and these logoi are enhuloi).

${ }^{27}$ In specifying these material features or aspects present within the form it should be assumed that terms such as 'particular type', 'certain structure', 'determinate types', 'certain conditions or states', etc. are merely dummy, or 'gappy' terms to be filled in, or made precise in a fully worked-out, scientific definition of the essence or form being human.

${ }^{28}$ This is why in the claims made in the previous two paragraphs the phrase 'essentially or necessarily?' is inserted in brackets to modify, and express openness about, the kind of intrinsic relation which obtains between the matter and the form.

${ }^{29}$ Phys. II.9, 200a5-15; 24-30.

${ }^{30}$ Phys. II.2, 193b31-194a7; Metaph. E.1, 1025b32-1026a6, esp. a2-3; Z.10, 1035b16-8;

Z.11, 1036b23-32. This issue is discussed in chapter 6 of Peramatzis, Priority.

${ }^{31}$ A sample list of passages which discuss the question of unity of natural compounds would include Phys. II.2, 194a15-b9; Metaph. Z.4, 1030a2-18; b4-13; Z.12 (together with APo. II.5, 91b28-92a5; II.6, 92a27-33; II.7, 92b4-11); Z.17, 1041b11-33; H.3, 1043b4-14; H.6.

${ }^{32}$ For modern defences of the spiritualist view see Frede M., 'The Definition of Sensible Substances in Met. Z', in D. Devereux and P. Pellegrin, (eds.), Biologie, Logique et Métaphysique chez Aristote, Éditions du CNRS, Paris; 1990, pp. 113-129; Devereux D., 
'Aristotle on the Form and Definition of a Human Being: Definitions and their Parts in Metaphysics Z.10 \& 11', Proceedings of the Boston Area Colloquium in Ancient Philosophy, 26, 2011; for a reply to Devereux see Code A., 'Commentary on Devereux', Proceedings of the Boston Area Colloquium in Ancient Philosophy, 26 (2011), 63-76.

33 Modern Aristotelian functionalists who seem to be taking the compound's unity as fundamental include Mary Louise Gill ('Unity of Definition in Metaphysics H.6 and Z.12' in Lennox J. G. \& Bolton R. (eds.), Being, Nature, and Life in Aristotle: Essays in Honor of Allan Gotthelf, CUP, Cambridge, 2010, pp. 97-121; 'Aristotle's Attack on Universals', OSAP 19, 2001, pp. 235-260; 'Matter against Substance', Synthese 96(3), 1993, pp. 379-397; Aristotle on Substance: The Paradox of Unity, Princeton, 1989), and (arguably) James Lennox (" "As if We Were Investigating Snubness": Aristotle on the Prospects for a Single Science of Nature', OSAP, 35, 2008, pp. 149-186). Jennifer Whiting, by contrast, despite following roughly the functionalist line, and emphasising the distinction between functional/proximate and remote matter, takes the form as primary, and as the source of the compound's unity (see her 'Living Bodies' in Nussbaum M. \& Rorty A. O. (eds.), Essays on Aristotle's De Anima, OUP, Oxford, 1992, pp. 75-92; 'Metasubstance: Critical Notice of Frede-Patzig and Furth', The Philosophical Review, 100(4), 1991, pp. 607-639; 'Form and Individuation in Aristotle', History of Philosophy Quarterly, 3(4), 1986, pp. 359-377).

${ }^{34}$ It is useful to compare this point with the discussion of the 'hyper-formalists' in Metaphysics Z.11, 1036a31-b23, alluded to earlier in section 4.

${ }^{35}$ For a recent argument in favour of essentially matter-involving forms see Peramatzis, Priority, esp. part I; also Charles D., 'Aristotle on Desire and Action' in Frede D. \& Reis B. (eds.), Body and Soul in Ancient Philosophy, De Gruyter, Berlin, 2009, pp. 291-308; 'Aristotle's Psychological Theory', Proceedings of the Boston Area Colloquium in Ancient Philosophy, 24, 2008, pp. 1-30; for a reply to Charles's view of Aristotle's psychological 
theory see Caston V., 'Commentary on Charles', Proceedings of the Boston Area Colloquium in Ancient Philosophy, 24, 2008, pp. 31-49.

${ }^{36}$ Indeed, Aristotle himself seems aware of the absurdity of a view which invokes talk of the essence of an essence, and thinks that his own position is not vulnerable to this sort of absurdity; see Metaph Z.6, 1031b28-1032a6.

${ }^{37}$ These distinctions are present in Categories 2 and 5. The view that species are prior to genera within the class of secondary substances is put forward at Categories 5, 2b7-14; 17 $22 ; 29-34$. Traces of the idea that the what-it-is (what Aristotle will call 'essence of' or' whatit-is-to-be- $x$ ' in his Metaphysics) of particular substances, as well as their species is something to be distinguished from secondary substances can be detected at Categories 5, 2b7-14; 29-37; 3a37-9; 3b2-4; 13-23.

38 The distinction between the primary substance that essence or form is, and type-objects such as the species human or horse is drawn clearly in Metaph. Z.10, 1035b13-31; see esp. 27-30.

${ }^{39}$ All of these works contain several discussions of the what-it-is, the essence, and the form using the suggestive terminology of to ti èn einai tōi $x$, or to einai $x$ (where 'tōi $x$ ' or ' $x$ ' are datives). Here are some examples: Topics I.5, 101b38-102a1; APo. II.4, 91a25; b8-9; II.8, 93a12-13; 19; II.11, 94a21; Metaph. Z.4, 1029b1-2; 13-14; 17-22; 1030a2-3; Z.17, 1041a2728.

${ }^{40}$ For further details about this view see Charles D., 'Some Remarks on Substance and Essence in Aristotle's Metaphysics Z.6' in Morison B. \& Ierodiakonou K. (eds.), Episteme, etc.: Essays in Honour of Jonathan Barnes, OUP, Oxford, 2011, pp. 151-171; and Peramatzis M., 'Essence and per se Predication in Aristotle's Metaphysics Z.4', Oxford Studies in Ancient Philosophy, 39, 2010, pp. 121-182 (esp. pp. 127-128, and nn. 8 \& 9). 
${ }^{41}$ There are several places in which Aristotle holds that the $F$, or $F$, is not the same as being $F$. Thus, for instance, while human soul (an essence or form) is identical with being a human soul, the man, or man, is not the same as being a man, or being a human soul. Presumably, this is because 'the man' (or 'man') signifies the kind or type-object, whereas 'being a man', 'human soul', 'being a human soul', etc. signify the essence or form. These are important claims as they suggest, first, that Aristotle conceives the relation between an essence-bearer and its essence as non-identity, and so as allowing for the priority of essence over the essence-bearer. Second, he takes the relation between the essence or form, and its own essence or nature as strict identity. Third, these two claims can be most plausibly understood as relying on the deep categorial distinction between token- or type-objects, on the one hand, and ways or modes of being, on the other. If so, it is not unreasonable to conclude that Aristotle himself favours this distinction, and understands essence or form in terms of an (essential) way or mode of being. Hence: Metaph. Z.10, 1035b33-1036a3 (the mathematical form being a circle and circle, as well as the natural form being a soul and soul, are tauta); Z.11, 1037a33-b3 (the primary substance, i.e. the essence, and its own essence is tauton; the example -expressed tentatively as it is a mathematical essence- is curvature and being a curvature); 1037b4-5 (the particular or universal compound, the essence-bearer, is ou tauto with its essence); H.3, 1043a37-b4 (one of the most important passages for the present issue: being a soul and soul are identical, but being a human (i.e. a human soul) and human are not identical, unless we speak in a qualified or attenuated manner, in which a human just is a soul); Topics V.4, 133b31-6 (human and being a human are not tauton; nor is pale human tauton with being a pale human).

${ }^{42}$ It is worth comparing this point with the discussion of section 1 about the role of 'primaries' and 'immediates' in Posterior Analytics II.8-9 (93a3-6; 93b21-5). Aristotle himself maintains that essence or form is such a primary, kath' hauto, and presumably 
'immediate' item in Metaph Z.6, 1031a28-30; b11-15; 1032a4-6; Z.11, 1037a33-b7. Furthermore, at Z.6, 1031a2829-30, he argues that there is no essence or nature prior to these items. At b11-13 he develops this idea by claiming that essence- or form-like items such as the Good or the Beautiful (these are Platonist, non-partisan, and neutral examples of kath' hauta or primaries) are one and the same as being Good or being Beautiful (presumably, these are the essential ways or modes of being that the Good and the Beautiful are, respectively, identical with). And at 1032a4-6 he concludes that there is an identity between the primary or kath' hauto that essence is and its own ti ên einai: in the case of prôta and kath' hauta, the hekastôi einai (x's essence) and the hekaston $(x)$ is to auto kai hen. Similarly, at Z.11, 1037a33-b3, the example of a primary (protê ousia) is an essence- or form-like item: curvature. Further, it is claimed that in the case of primaries 'each thing' is the same as the $t i$ ên einai (to ti ên einai kai hekaston epi tinôn men tauto, hôsper epi tôn prôtôn ousiôn, hoion kampulotês kai kampulotêti einai): curvature, an essence-like item, is identical with being a curvature, i.e. with the essence it is one and the same as. As 1037b4-5 suggests, by contrast, token- or type-compounds are not identical with their essences, but are essence-bearers: they have but are not (the same as) essences.

${ }^{43}$ APo. II.9, 93b24-5.

${ }^{44}$ The problem of repetition and babbling, as it applies particularly to material terms of the definiens, is raised usually by reference to Aristotle's pet example of a hylomorphic compound, the snub-nose, snubness, or being snub: Soph. El. 13, 173b9-11; 31, 181b35182a6; Metaph. Z.5, 1030b28-1031a1.

\section{Bibliography}

Bolton R., 'Essentialism and Semantic Theory in Aristotle: Posterior Analytics II.7-10', Philosophical Review 85, 1976, pp. 514-544. 
Bolton R., 'Biology and Metaphysics in Aristotle' in Lennox J. G. \& Bolton R. (eds.), Being, Nature, and Life in Aristotle: Essays in Honor of Allan Gotthelf, CUP, Cambridge, 2010, pp. $30-55$.

Caston V., 'Commentary on Charles', Proceedings of the Boston Area Colloquium in Ancient Philosophy, 24, 2008, pp. 31-49.

Charles D., 'Some Remarks on Substance and Essence in Aristotle's Metaphysics Z.6' in Morison B. \& Ierodiakonou K. (eds.), Episteme, etc.: Essays in Honour of Jonathan Barnes, OUP, Oxford, 2011, pp. 151-171. , 'Aristotle on Desire and Action' in Frede D. \& Reis B. (eds.), Body and Soul in Ancient Philosophy, De Gruyter, Berlin, 2009, pp. 291-308. 'Aristotle's Psychological Theory', Proceedings of the Boston Area Colloquium in Ancient Philosophy, 24, 2008, pp. 1-30. Aristotle on Meaning and Essence, Oxford, OUP, 2000.

Code A., 'Commentary on Devereux', Proceedings of the Boston Area Colloquium in Ancient Philosophy, 26 (2011), 63-76.

Devereux D., 'Aristotle on the Form and Definition of a Human Being: Definitions and their Parts in Metaphysics Z.10 \& 11', Proceedings of the Boston Area Colloquium in Ancient Philosophy, 262011.

Frede M., 'The Definition of Sensible Substances in Met. Z', in D. Devereux and P. Pellegrin, (eds.), Biologie, Logique et Métaphysique chez Aristote, Éditions du CNRS, Paris; 1990, pp. 113-129.

Gill M.L., 'Unity of Definition in Metaphysics H.6 and Z.12' in Lennox J. G. \& Bolton R. (eds.), Being, Nature, and Life in Aristotle: Essays in Honor of Allan Gotthelf, CUP, Cambridge, 2010, pp. 97-121. 'Aristotle's Attack on Universals', OSAP 19, 2001, pp. 235-260. 
, 'Matter against Substance', Synthese 96(3), 1993, pp. 379-397. , Aristotle on Substance: The Paradox of Unity, Princeton, 1989.

Lennox J., “ "As if We Were Investigating Snubness”: Aristotle on the Prospects for a Single Science of Nature', OSAP, 35, 2008, pp. 149-186.

Peramatzis M., Priority in Aristotle's Metaphysics, OUP, Oxford, 2011. , 'Essence and per se Predication in Aristotle's Metaphysics Z.4', Oxford

Studies in Ancient Philosophy, 39, 2010, pp. 121-182.

Ross W.D., Aristotle’s Prior and Posterior Analytics, Oxford, OUP, 1949

Whiting J., 'Living Bodies' in Nussbaum M. \& Rorty A. O. (eds.), Essays on Aristotle's De Anima, OUP, Oxford, 1992, pp. 75-92.

, 'Metasubstance: Critical Notice of Frede-Patzig and Furth', The Philosophical Review, 100(4), 1991, pp. 607-639. , 'Form and Individuation in Aristotle', History of Philosophy Quarterly, 3(4), 1986, pp. 359-377.

Williams St. \& Charles D., 'Essence, Modality and the Master Craftsman' in Feser Ed. (ed.), Aristotle on Method and Metaphysics, Palgrave-MacMillan, 2013. 